\title{
MIRÍDEOS NEOTROPICAIS CCCXC: ESPÉCIES NOVAS DE GOIÁS (HEMIPTERA, MIRIDAE)
}

\author{
José C. M. Carvalho ${ }^{1,2}$ \\ Luiz A. A. Costa 1
}

\begin{abstract}
NEOTROPICAL MIRIDAE CCCXC: NEW SPECIES FROM GOIÁS (HEMIPTERA, MIRIDAE). Six new species from Campinaçu, Goiás (Hemiptera) are described: Notholopus (Notholopoides) niger, sp.n., T. tripallidus, sp.n., Prepops goianus, sp.n., P. semifemoratus, sp.n., Poeas clavata, sp.n. and Taedia goiana, sp.n.

KEY WORDS. Hemiptera, Miridae, new species, Goiás, Brazil
\end{abstract}

Seis espécies novas de Miridae (Hemiptera) de Campinaçu, Goiás, são descritas.

Os desenhos do texto foram feitos por Maria Lilia Gomide da Silva e por Paulo Roberto Nascimento, as genitálias foram desenhadas pelo segundo autor, sob supervisão do primeiro.

\section{Notholopus (Notholopoides) niger, sp.n.}

Figs 1-5

Holótipo macho. Brasil, Goiás, Campinaçu, X.1992, O. Roppa leg, Coleção de Entomologia do Museu Nacional. Parátipo fêmea. Brasil, Goiás, Campinaçu, X.1992, O. Roppa leg, coleção particular do autor senior.

Diagnose. Reconhecível pela coloração do corpo e pela morfologia da genitália do macho.

Descrição. Medidas em milímetros. Corpo comprimento e largura 6,2: 3,8. Cabeça comprimento e largura $0,6: 1,2$; vértice 0,50 . Antena comprimento dos segmentos I, II, III e IV 0,9:2,1:0,8:1,0. Pronoto comprimento e largura da base 1,4:2,4. Cúneo comprimento e largura na base 1,1:0,8 (holótipo).

Coloração geral do corpo preta acastanhada; segmentos III e IV da antena pálida na extrema base, clípeo preto, rostro da mesma cor. Pronoto com duas manchas pretas após os calos. Hemiélitros da coloração geral do corpo; veias da membrana pálidas. Lado inferior do corpo com margem da propleura clara, preto parte posterior do mesosterno e peritrema ostiolar mais claros, coxas mais escuras, fêmures inferiormente com pequenas manchas brancas,

1) Museu Nacional, Universidade Federal do Rio de Janeiro, Quinta da Boa Vista, São Cristóvão, 20940-040 Rio de Janeiro, Rio de Janeiro, Brasil.

2) Pesquisador do CNPq. 
5
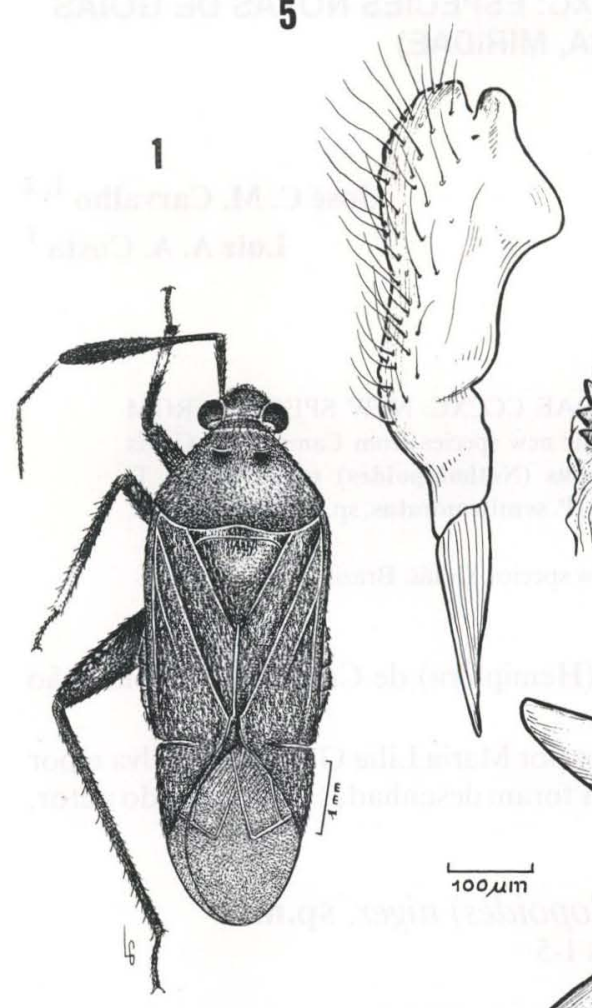

2

2

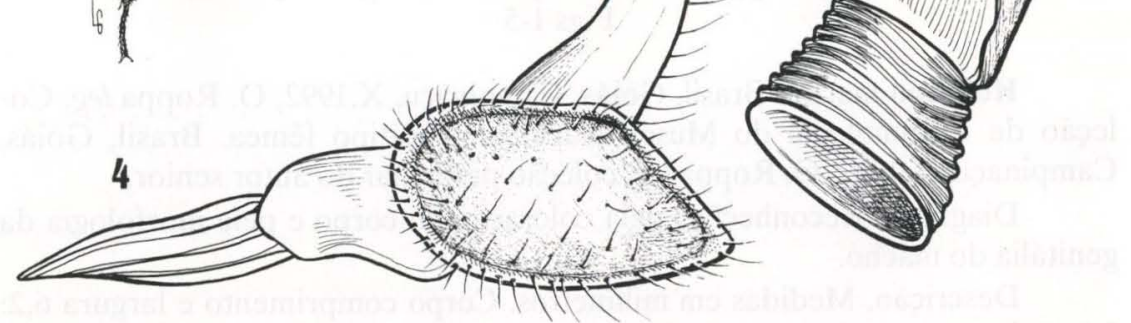

Figs 1-5. Notholopus (Notholopoidea) niger, sp.n. (1) Holótipo; (2) vesica; (3) cabeça da vesica, lado esquerdo; (4) parâmero esquerdo; (5) parâmero direito.

tíbias escuras. Rostro alcançando as coxas posteriores.

Genitália. Vesica (Figs 2,3) com espículo ramificado no ápice e um lobo menor denteado, lobos como mostra a ilustração. Parâmero esquerdo (Fig. 4) com lobo subasal muito grande, curvo e coberto de pêlos, ápice alargado. Parâmero direito (Fig. 5) com bifurcação apical, mais alargado próximo ao ápice e pêlos dorsais.

Fêmea. Pouco maior que o macho, com a mesma coloração, vértice 0,60 .

O nome específico é alusivo a coloração preta-acastanhada. 
6

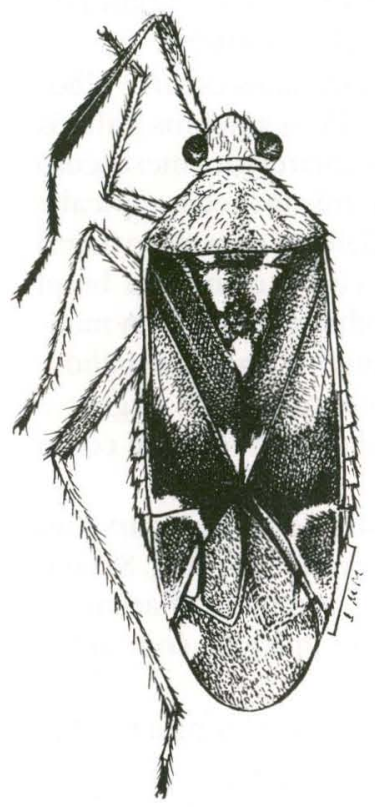

9

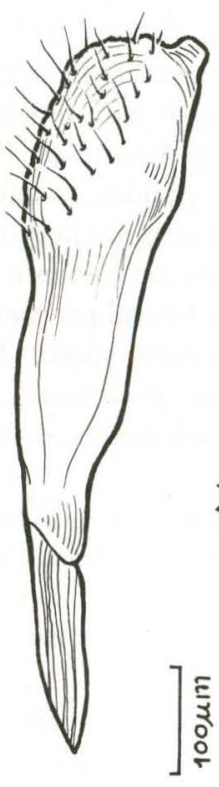

7

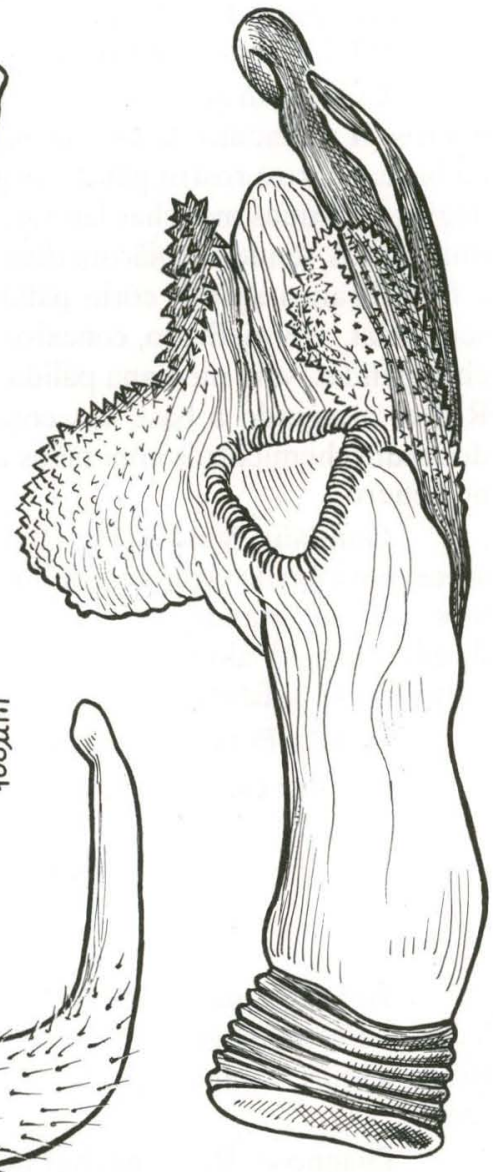

Figs 6-9. Notholopus tripallidus, sp.n. (6) Holótipo; (7) vesica; (8) parâmero esquerdo; (9) parâmero direito.

\section{Notholopus tripallidus, sp.n.}

Figs 6-9

Holótipo macho. Brasil, Goiás, Campinaçu, X.1992, O. Roppa leg, Coleção de Entomologia do Museu Nacional. Parátipos. Cinco machos e 15 fêmeas. Brasil, Goiás, Campinaçu, X.1992, O. Roppa leg, coleção particular do autor senior.

Diagnose. Reconhecível pela coloração do escutelo e pela morfologia da genitália do macho.

Descrição. Medidas em milímetros. Corpo comprimento e largura 5,6: 
2,4. Cabeça comprimento e largura 0,2:1,2; vértice 0,50. Antena comprimento dos segmentos I, II, III e IV 1,1:1,8:0,8:0,9. Pronoto comprimento e largura da base 1,0:1,2. Cúneo comprimento e largura na base 0,6:0,3 (holótipo).

Coloração geral do corpo amarelada com hemiélitro mais escuro; olhos negros, II segmento da antena negro para o ápice, III e IV segmentos pálidos na base, negros; rostro pálido, negro no ápice. Pronoto amarelado, mesoscuto negro, com duas manchas laterais pálidas, escutelo com três manchas: apical e duas basais, tendo a região mediana e lados negros. Hemiélitros com clavo negro e faixa branca apical, cório pálido no extremo ápice, cúneo com faixa basal semilunal, avermelhado, conexivo lateral presente, membrana fusca com manchas pálidas, veia mediana pálida para o ápice. Lado inferior do corpo pálido. Rostro atingindo a base das coxas posteriores, pronoto com pêlos negros e dourados, hemiélitros com pêlos adpressos, escutelo saliente, o restante como no gênero.

Genitália. Vesica (Fig. 7) com dois espículos laterais, um deles curvo no ápice, um lobo de espinhos e lobos espinhosos. Parâmero esquerdo (Fig. 8) com lobo subasal grande, recoberto de pêlos, curvo, ápice rombudo. Parâmero direito (Fig. 9) alongado, recoberto de pêlos na porção apical e com ápice esclerosado, saliente.

Fêmea. Pouco maior que o macho, corpo comprimento e largura 6,8:4,2.

$\mathrm{O}$ nome específico é alusivo às três manchas pálidas no escutelo.

\section{Prepops goianus, sp.n.}

Figs 10-13

Holótipo macho. Brasil, Goiás, Campinaçu, X.1992, O. Roppa leg, Coleção de Entomologia do Museu Nacional. Parátipos. Dois machos e uma fêmea. Brasil, Goiás, Campinaçu, X.1992, O. Roppa leg, coleção particular do autor senior.

Diagnose. Reconhecível pela coloração do corpo e pela morfologia da genitália do macho.

Descrição. Medidas em milímetros. Corpo comprimento e largura 5,2: 1,8. Cabeça comprimento e largura 0,3:1,0; vértice 0,50. Antena comprimento dos segmentos I, II, III e IV 0,4:1,4:0,6:0,3. Pronoto comprimento e largura da base 0,7:1,5. Cúneo comprimento e largura na base 0,8:0,5 (holótipo).

Coloração geral do corpo lútea e preta; cabeça clara, olhos negros, antena preta, segmento I pálido na base, lados da cabeça pálidos, rostro pálido. Pronoto com duas manchas negras, sublaterais, mesoscuto e escutelo amarelos e lúteos. Hemiélitros pretos no clavo e endocório, membrana fusca. Lado inferior do corpo pálido. Rostro atingindo um pouco além das coxas posteriores, pêlos do lado superior obsoletos, olhos salientes para fora.

Genitália. Vesica (Fig. 11) com dois espículos centrais, uma área esclerosada, um lóbulo fino, recoberto de dentículos, e outro maior, também recoberto de dentículos. Parâmero esquerdo (Fig. 12) curvo, com pêlos dorsais esparsos, 
sem placa basal. Parâmero direito (Fig. 13) mais alargado no meio, com pêlos dorsais e ápice fino e esclerosado.

Fêmea. Igual ao macho em cor e dimensões. cionados.

O nome específico é alusivo ao Estado no qual os tipos foram cole-
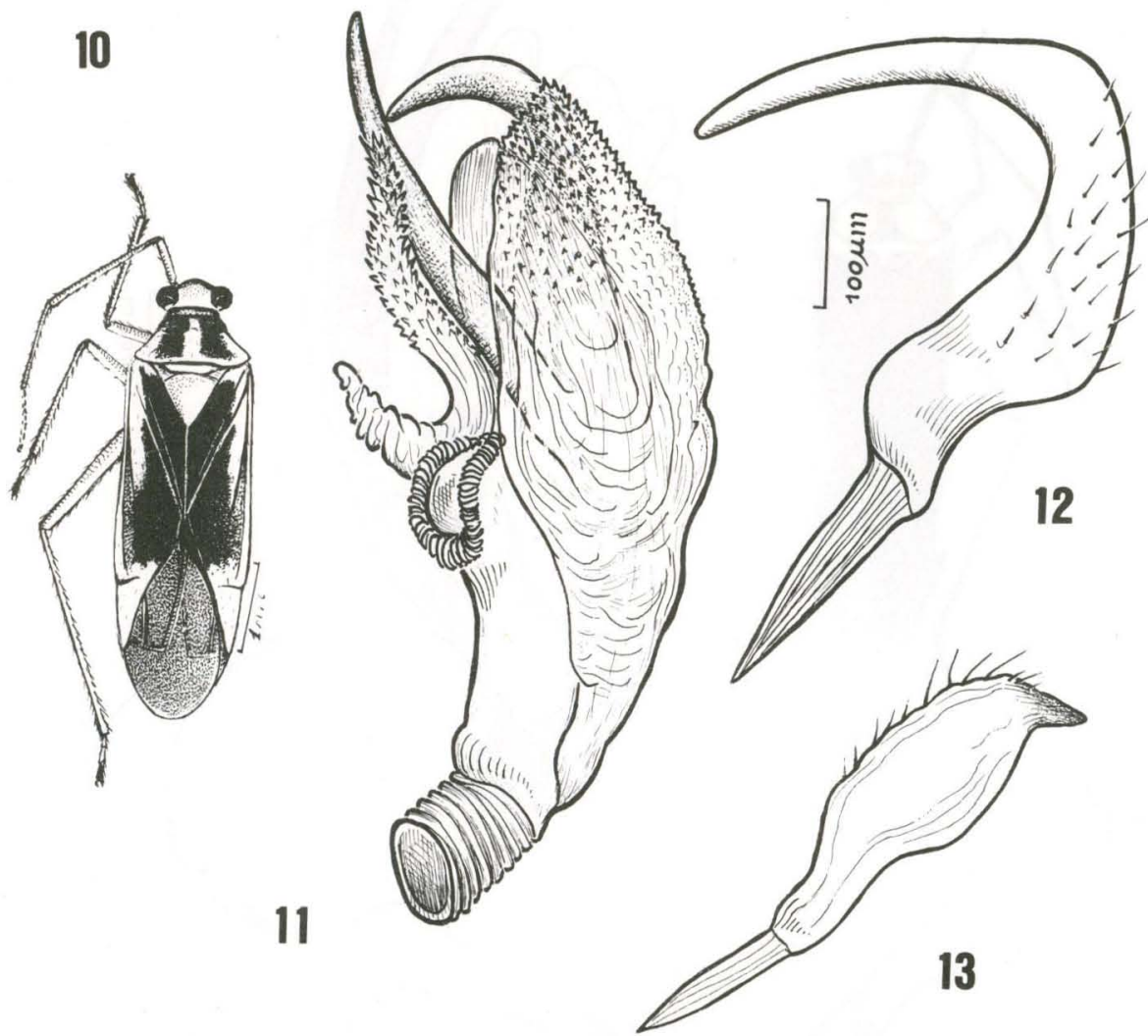

Figs 10-13. Prepops goianus, sp.n. (10) Holótipo; (11) vesica; (12) parâmero esquerdo; (13) parâmero direito.

\section{Prepops semifemoratus, sp.n.}

Figs 14-17

Holótipo macho. Brasil, Goiás, Campinaçu, X.1992, O. Roppế, leg, Coleção de Entomologia do Museu Nacional. Parátipo fêmea. Brasil, Goiás, Campinaçu, X.1992, O. Roppa leg, coleção particular do autor senior. macho.

Diagnose. Reconhecível pela coloração e pela morfologia da genitália do

Descrição. Medidas em milímetros. Corpo comprimento e largura 6,8: 
1,8. Cabeça comprimento e largura $0,4: 1,2$; vértice 0,42 . Antena comprimento dos segmentos I, II, III e IV 0,8:2,5:0,7:1,0. Pronoto comprimento e largura da base 1,0:1,8. Cúneo comprimento e largura na base 1,1:0,6 (holótipo).
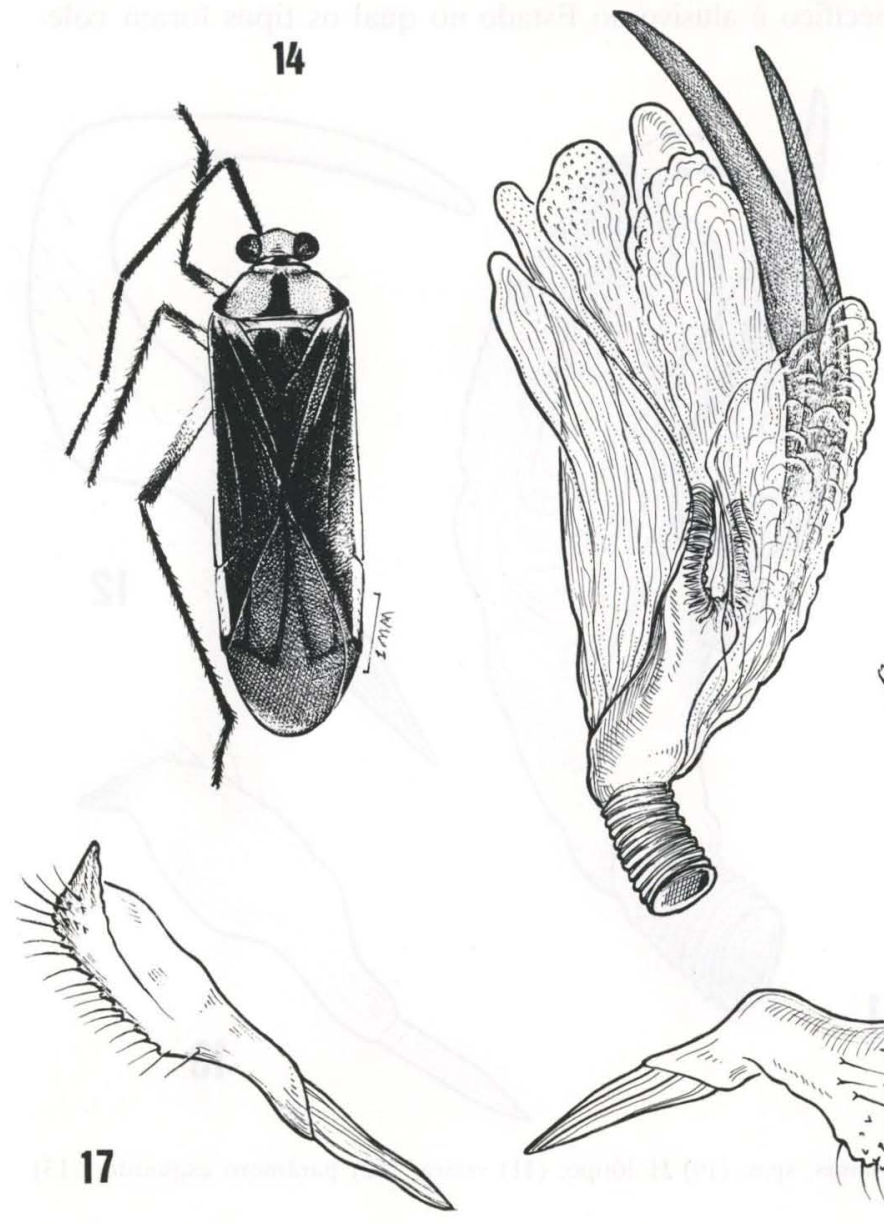

15

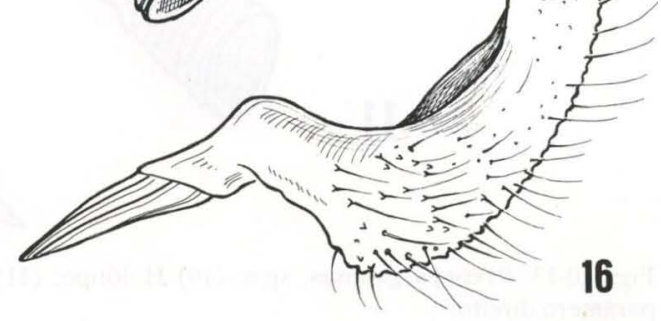

Figs 14-17. Prepops semifemuratus, sp.n. (14) Holótipo; (15) vesica; (16) parâmero esquerdo; (17) parâmero direito.

Coloração geral do corpo preta e lútea; cabeça lútea, antenas (exceto a base do segmento I) pretas, clípeo preto, rostro pálido, ápice preto. Pronoto lúteo, com calos e uma faixa mediana, meio do colar e ângulos umerais pretos; mesoscuto lúteo, escutelo preto, lúteo no meio da base. Hemiélitros pretos, embólio e cúneo externamente lúteos. Lado inferior do corpo lúteo, pigóforo negro, pernas (exceto meio dos fêmures lúteo-pálido) pretas. Rostro piloso no segmento I, atingindo o meio das coxas posteriores. 
Genitália. Vesica (Fig. 15) com dois espículos laterais e lobos simples e com dentículos, tubo seminal secundário curto. Parâmero esquerdo (Fig. 16) com um dente pré-apical, pêlos dorsais e uma aba no meio. Parâmero direito (Fig. 17) simples, com pêlos dorsais saindo de minúsculos tubérculos, ápice esclerosado e pontudo.

Fêmea. Igual ao macho em cor e dimensões, vértice 0,50 .

$\mathrm{O}$ nome específico é alusivo à coloração do fêmur.

\section{Poeas clavata, sp.n.}

Figs 18-22

Holótipo macho. Brasil, Goiás, Campinaçu, X.1992, O. Roppa leg, Coleção de Entomologia do Museu Nacional. Parátipos. Dois machos. Brasil, Goiás, Campinaçu, X.1992, O. Roppa leg, coleção particular do autor senior. macho.

Diagnose. Reconhecível pela cor e pela morfologia da genitália do

Descrição. Medidas em milímetros. Corpo comprimento e largura 6,4: 3,0 . Cabeça comprimento e largura $0,5: 1,2$; vértice 0,58 . Antena comprimento dos segmentos I, II, III e IV 1,1:2,6:1,0:0,8. Pronoto comprimento e largura da base 1,2:2,6. Cúneo comprimento e largura na base 1,0:0,6 (holótipo).

Coloração geral do corpo rubro superiormente com duas manchas pretas no clavo; olhos avermelhados, cabeça, pronoto e escutelo amarelados, base do hemiélitro da mesma cor, sutura do clavo internamente negra, ápice claro, cório vermelho na parte apical, membrana fusca, veias salientes, pouco mais claras. Lado inferior do corpo pálido. Rostro atingindo a base das coxas posteriores, tíbias posteriores com espinhos mais curtos que sua grossura.

Genitália. Vesica (Fig. 19) com dois espículos centrais, lobos lisos e um campo de dentículos internamente, orifício genital secundário largo e tubo genital longo. Parâmero esquerdo (Fig. 20) curvo para dentro, afilado para o ápice, recoberto de pêlos, placa subasal grande, também recoberta de pêlos. Parâmero direito (Figs 21, 22) coberto de pêlos, com um dente esclerosado apical.

Fêmea desconhecida.

O nome específico é alusivo à cor do clavo.

\section{Taedia goiana, sp.n.}

Figs 23-26

Holótipo macho. Brasil, Goiás, Campinaçu, X.1992, O. Roppa leg, Coleção de Entomologia do Museu Nacional. Parátipo fêmea. Brasil, Goiás, Campinaçu, X.1992, O. Roppa leg, coleção particular do autor senior.

Diagnose. Reconhecível pela coloração do escutelo e pela morfologia da genitália do macho.

Descrição. Medidas em milímetros. Corpo comprimento e largura 5,0: 


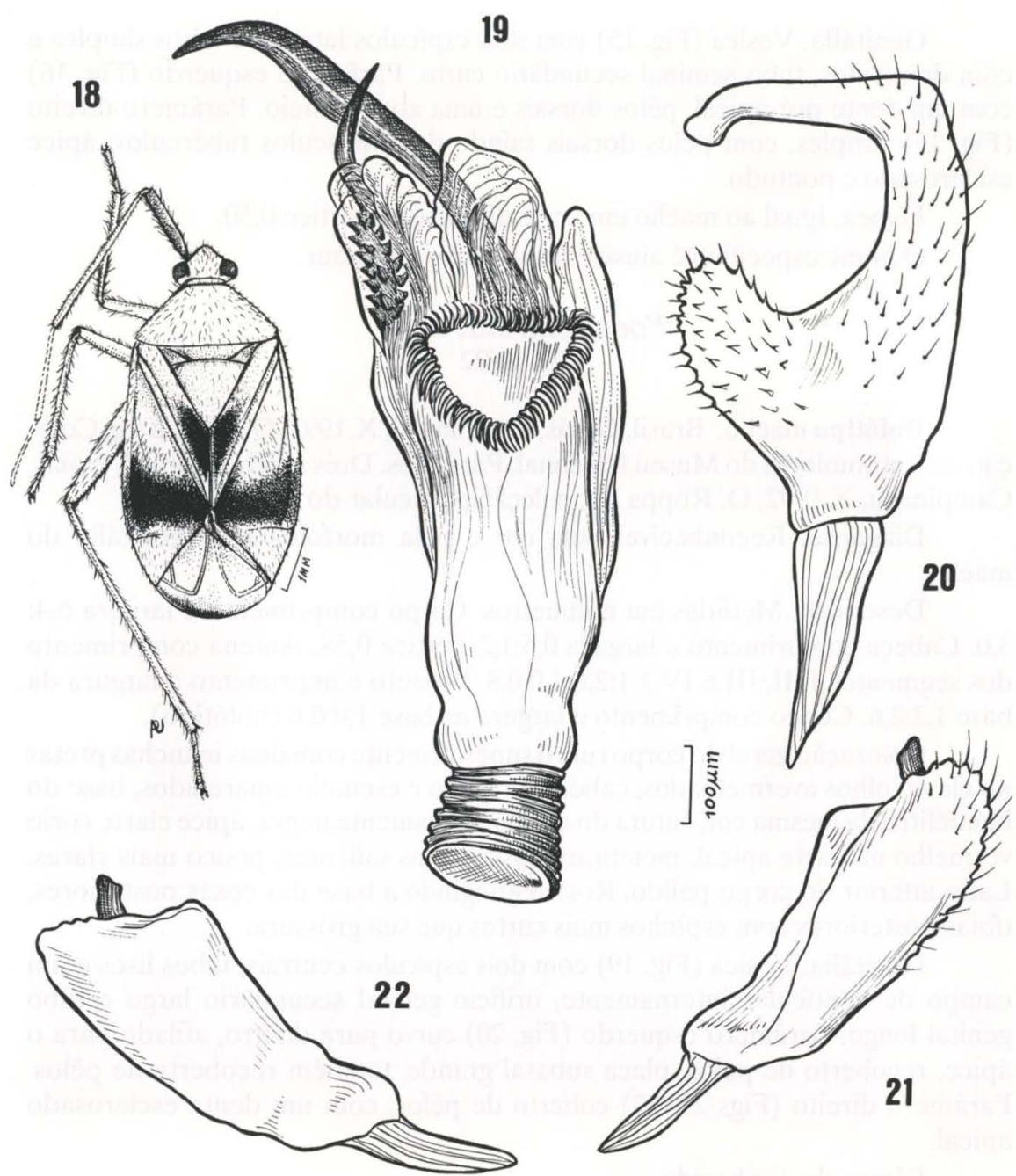

Figs 18-22. Poeas clavata, sp.n. (18) Holótipo; (19) vesica; (20) parâmero esquerdo; $(21,22)$ Parâmero direito.

2,2. Cabeça comprimento e largura $0,3: 1,1$; vértice 0,20 . Antena comprimento dos segmentos I, II, III e IV 0,7:1,8:0,7:0,9. Pronoto comprimento e largura da base 0,8:1,1. Cúneo comprimento e largura na báse 1,0:0,6 (holótipo).

Coloração geral do corpo cor de tijolo com áreas pretas; segmento I da antena manchado, com ápice preto, segmento II negro, segmento III pálido, mais claro na base; segmento IV pálido; rostro pálido, ápice negro. Pronoto com duas manchas pretas atrás dos calos, margem posterior submarginalmente 


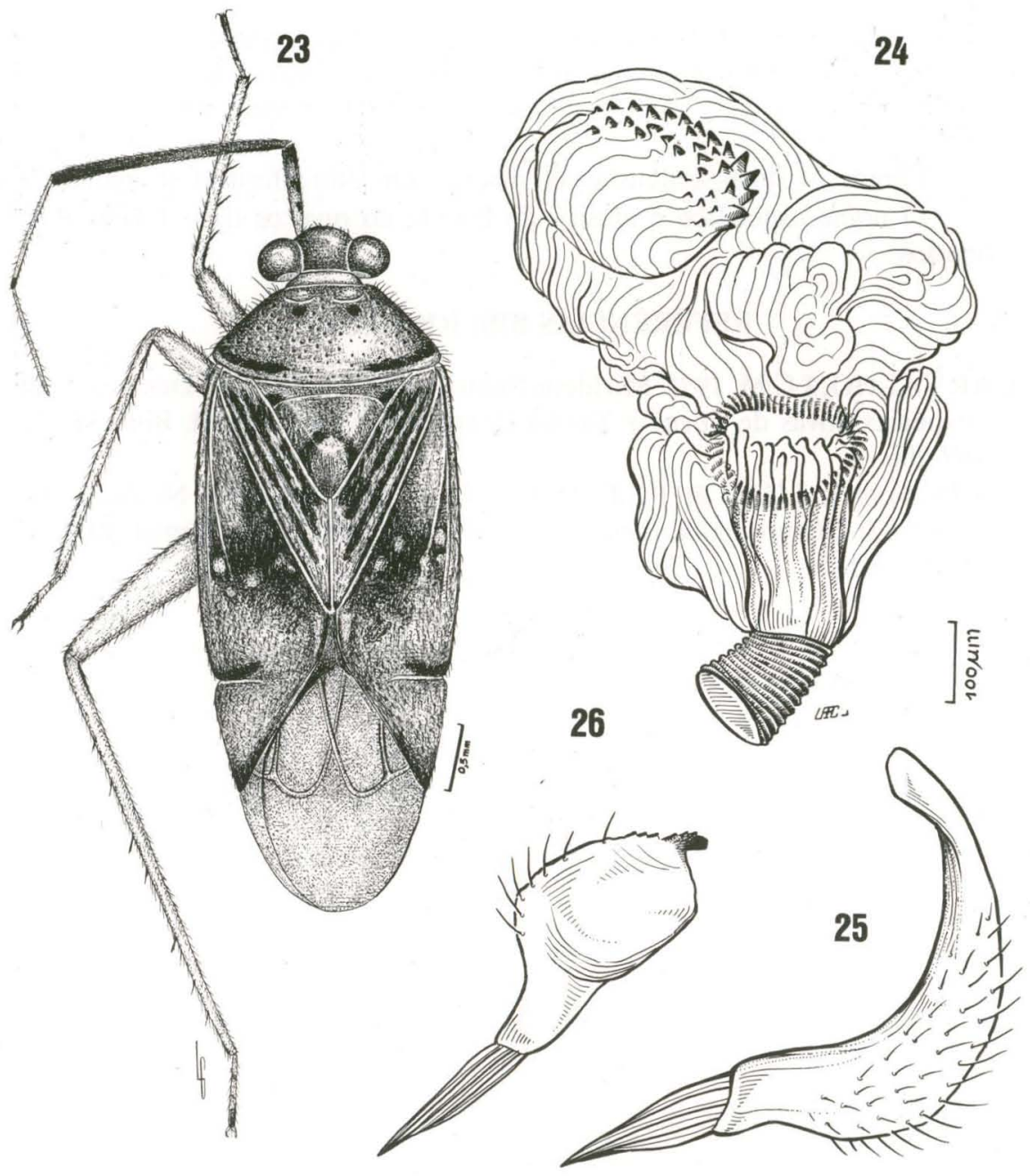

Figs 23-26. Taedia goiana, sp.n. (23) Holótipo; (24) vesica; (25) parâmero esquerdo; (26) parâmero direito, ápice.

preta, pálidas no ápice; mesoscuto preto, escutelo amarelo com duas manchas negras alongadas subapicais. Hemiélitros com clavo preto, sutura claval da cor do hemiélitro que é tijolo, endocório negro com prolongamento externo tendo duas manchas da cor do hemiélitro, ápice do cório na região emboliar negra, cúneo pálido com margem interna no ápice levemente negra, membrana fusca, veias negras. Lado inferior do corpo pálido, pigóforo negro. Rostro ultrapassando pouco as coxas posteriores.

Genitália. Vesica (Fig. 24) com tubo seminal distal curto, com lobos 
membranosos e um lobo serreado, como mostra a figura. Parâmero esquerdo (Fig. 25) curvo, simples e com ápice dilatado; parâmero direito (Fig. 26) alargado para o ápice, com pêlos dorsais e ápice esclerosado, terminando em ponta.

Fêmea. Mesmas dimensôes do macho, com lado inferior todo pálido. cionados.

O nome específico é alusivo ao Estado no qual os tipos foram cole-

\section{REFERÊNCIAS BIBLIOGRÁFICAS}

CARVALHO, J.C.M. 1975. Mirídeos Neotropicais, CLXXXIX: Descrições de espécies novas de Poeas e Taedia (Hemiptera). Rev. Brasil. Biol. 35 (2): 67-206.

CARVALHO, J.C.M. \& P.S.F. FERREIRA. 1971. Mirídeos Neotropicais, CXXXI: Gênero Notholopus Bergroth (Hemiptera). Rev. Brasil. Biol. 31 (2): 165-173.

Recebido em 13.V.1993; aceito em 30.VIII.1993. 